\title{
Evaluation of Oxidative Markers, Apoptosis and Reproductive Efficiency in Heroin Addicted Rats
}

\author{
Goran Qader Othman \\ Medical laboratory department/Medical technical institute-Hawler Polytechniques University
}

\begin{abstract}
:
Background and Objective: Heroin abuse and addiction represent one of the major problems globally. The objective of this study is to evaluate the oxidative stress enzyme markers, apoptosis, sperm quality and testosterone of heroin administered rats via intraperitoneal injection.
\end{abstract}

MATERIALS AND METHODS: Thirty male rats were randomly allocated into three groups. Frst group regarded as control, while in group2 and 3, the animals were daily injected intraperitoneally with (1 and $5 \mathrm{mg}$ Heroin/kg b.w.) for seven successive days. Enzymatic activities of alkaline phosphatase (ALP), Xanthine Oxidase (XO), Glucose-6-phosphate dehydrogenase (G6PDH) and lactate dehydrogenase ( $L D H)$ in serum were analyzed, and concentration of Malondialdehyde (MDA) and testosterone hormone assayed, besides determining the percent count of hepatocyte apoptosis and sperm head abnormalities.

RESULTS: The activity of XO, G6PDH and LDH significantly changed, whereas ALP not affected. The lipid peroxidation marker (MDA) significantly elevated in high dose treatment. The mean percent of apoptotic hepatocytes count reported a clear increase in concentration dependent manner. Also heroin showed significant impact on testosterone level, and sperm head abnormalities counting as well.

CONCLUSION: This finding suggests that intraperitoneal injection of heroin cause alteration in oxidation processes, reproductive efficiency and apoptosis mostly in concentration dependent manner.

KEYWORDS: Heroin-Oxidative stress-Testosterone-Sperm-Apoptosis - Rats

\section{BACKGROUND}

Heroin abuse is considered to be the major clinical problem in the age between 25 to 49 years-old. In most countries, drug overdose is the main leading cause of death, on a part with motor vehicle accidents ${ }^{(1)}$. Heroin dependence, is a chronic illness that, when untreated, can result in adverse health consequences such as blood-borne viral infections, endocarditis and drug overdoses ${ }^{(2,3)}$. With more than 20 million heroin addicts estimated worldwide and countless others addicted to prescription opioids, drug addiction remains a large public health problem ${ }^{(4)}$.It was pointed out that The balance between oxidation and antioxidation in the heroin abusers was seriously destroyed, and the injuries induced by nitric oxide and other free radicals, oxidation, peroxidation and lipoperoxidation reactions to the body of heroin abusers gravely exacerbated ${ }^{(5)}$ and the oxidative stress produced by heroin was directly proportional to heroin-abusing-duration (HAD) and daily-heroin-abusingquantity ${ }^{(6,7)}$. In the study of ${ }^{(8)}$ reported that morphine triggered apoptosis of peripheral blood mononuclear cells from healthy subjects. Moreover, other studies have suggested that monocytes provide soluble Fas, which has the potential to trigger lymphocyte apoptosis ${ }^{(9)}$. Whereas ${ }^{(10)}$ provides further support for the hypothesis that morphine may be directly compromising immune function by enhancing apoptosis of $\mathrm{T}$ lymphocytes in patients with heroin addiction through alteration of $\mathrm{BCl} 2$ and $\mathrm{BAX}$ genes expression. Some studies demonstrated that high-dose methadone was shown to depress plasma testosterone levels ${ }^{(11,12)}$, and other clinical studies have reported decreased sexual drive and performance in male heroin addicts ${ }^{(13)}$. This study is designed for better understanding of the underlying mechanisms of heroin-induced toxicity which may allow more informed application of opioid replacement therapy as well as the development of additional novel therapeutic interventions.

Animals

\section{MATERIALS AND METHODS}

Adult male albino rats Rattus norvegicus were bred in the animal house of Biology Dept. /College of Science/University of Salahaddin. In the present study 30 healthy rats weight about (200-250) gram were used in this study. 


\section{Experimental protocol}

In this experiment the animals were randomly allocated to three experimental groups of 10 rats in each group for seven days: (1) the rats of this group were received tab water and regarded as control group. The animals were injected with normal saline. (2) the rats of the second group daily injected intraperitoneally with $\left(1 \mathrm{mg}\right.$ Heroin/kg b.w.) ${ }^{(14)}$. (3) the rats of third group were injected daily intraperitoneally with daily (5mg Heroin/kg b.w.) ${ }^{(15)}$.

\section{Drug Preparation:}

An appropriate amount of brown Heroin (Diamorphine or Diacetyl-morphine) was provided by directorate of narcotics control in Erbil province-Iraq. For injection Lab. preparation, amount of 250mg of Heroin powder was mixed $25 \mathrm{mg}$ of citric acid (BDH company). The mixture dissolved in $0.8 \mathrm{ml}$ of distilled water at $40 \mathrm{C} \dot{\circ}$, mixed well via using tip of needle sheath, then the solution heated over a flame until bubbles produced $^{(16)}$ and the remaining solution was drawn by $1 \mathrm{ml}$ syringe (needle G29) and diluted to (5mg/ml). Each $1 \mathrm{ml}$ was injected to $1 \mathrm{~kg}$ b.w. rats $(5 \mathrm{mg}$ Heroin $/ \mathrm{kg}$ b.w. rats), while further dilution was made for the other dose by resuspending the stock solution in D.W.

\section{Serum enzymatic analysis}

Blood samples were taken into glass bottles with rubber caps, labelled and centrifuged at $4000 \mathrm{~g}$ for 10 min. Serum enzyme [Alkaline phosphatase (ALP), Xanthine Oxidase (XO), Glucose-6-phosphate dehydrogenase (G6PDH) and lactate dehydrogenase (LDH)] were assayed using colorimetric specific kits for each enzyme.

\section{Determination of serum malondialdehyde (MDA):}

The assessment of the lipid peroxidation process is done by determination of the end product, malondialdehyde ${ }^{(17)}$. The level of serum MDA was determined spectrophotometrically, in brief , $150 \mu 1$ of serum sample was mixed with $1 \mathrm{ml}$ trichloroacetic acid (TCA) $17.5 \%$ and $1 \mathrm{ml}$ of $0.66 \%$ thiobarbituric acid (TBA), then vortexed, incubated in boiling water for 15 minutes, and allowed to cool. After that one $\mathrm{ml}$ of $70 \%$ TCA was added. The mixture was allowed to sit at room temperature for 20 minutes. Then the sample centrifuged at $2000 \mathrm{rpm}$ for 15 minutes, and the supernatant absorbency was read spectrophotometrically at $532 \mathrm{~nm}$ wavelength.

\section{Testosterone Assay}

Serum concentration of total testosterone were measured for all samples using an automated quantitative system (Mini Vidas; bioMerieux, Lyon,France). All samples were analyzed using the enzyme linked fluorescent assay technique, an enzyme immunoassay sandwich method with a final fluorescent detection.

\section{Sperm preparation}

The sperms were prepared from epididymis and vas deference. After killing the animals, the epididymis and vas deference were removed from the testes and transferred in to small petridish containing normal saline. By using a sharp scissor the epididymis and vas deference were cut in to several parts, the sperms were released into the saline solution. The sperm suspension were smeared and dried, fixed with fixative, finally stained with $1 \%$ Eosin stained for 5 min. the slide washed by distilled water and were left to dry ${ }^{(18)}$.

\section{Histological examination for detecting apoptosis frequency}

After removal of the liver, small portions were immediately fixed in $10 \%$ formalin and embedded in paraffin ; $5 \mathrm{~mm}$ thick sections were stained with hematoxylin and eosin ${ }^{(19)}$. Apoptotic cells were counted. The frequencies were determined by scoring 1000 hepatocytes per liver. Only apoptotic bodies containing nuclear fragments were considered ${ }^{(20)}$.

\section{Statistical analysis:}

Data were expressed as means \pm standard error $(\mathrm{M} \pm \mathrm{SE})$ and statistical analysis was conducted using statistically available software (SPSS 17 for Windows 7). Data analysis was made using one-way analysis of variable (ANOVA). The comparison between groups were done using Duncan post hoc test. Differences were considered significant when $P$ values were $<0.05$ and $<0.01$. 


\section{RESULTS AND DISCUSSION:}

Effect of Heroin on the serum enzymes activity:

The current study results demonstrated that heroin addiction significantly increased the activity of serum xanthine oxidase $(\mathrm{P}<0.01)$ as shown in table (1). The induction of XO activity by heroin was concentration dependent. The levels of XO were $(21.2 \pm 2.244)$ and $(30.4 \pm 2.158)$ in rats treated with $1 \mathrm{mg}$ and $5 \mathrm{mg}$ heroin respectively as illustrated $\mathrm{n}$ figure (1). It has been postulated that Heroin administration may enhance the catabolism and inhibit the anabolism of purine nucleotides through significantly increasing of ADA and $\mathrm{XO}$ activities and the mRNA level of Adenosine deaminase (ADA) and XO in brain tissues in heroin group (21) Also, the investigation performed by ${ }^{(22)}$ showed that during morphine administration, the levels of plasma ADA and XO increased significantly when compared to the control, and after morphine withdrawal, the concentration of these two enzymes were still remained high.Statistical analysis of ALP results demonstrated that both concentrations of heroin didn't significantly changed the ALP levels with mean values $(8.61 \pm 1.05)$ and $(6.11 \pm 0.77)$ of heroin $1 \mathrm{mg}$ and $5 \mathrm{mg}$ respectively, as compared to the control treatment $(9.49 \pm 1.06)$ as shown in figure (2). Liver damage from heroin has been proved in numerous studies worldwide ${ }^{(23-31)}$. The addiction of heroin or morphine affects the liver function enzyme as a whole ${ }^{(32)}$, but most of the studies concentrate on the evaluation of aminotransferases rather than phosphatase enzymes.

Table (1) also summarizes the action of heroin addiction on the activity of serum G6PDH and LDH. The activity of G6PDH was significantly decreased in a concentration dependent manner. The mean values were $(1.28 \pm 0.15)$ and $(0.369 \pm 0.049)$ in rats treated with $1 \mathrm{mg}$ and $5 \mathrm{mg}$ heroin respectively as compared to the control value $(0.246 \pm 0.29)$ as shown in figure (3). While significant induction of LDH activity were reported in both $1 \mathrm{mg}$ and $5 \mathrm{mg}$ heroin treatments with means $(662.4 \pm 150.6)$ and $(1007.8 \pm 208.4)$ respectively as compared to control value which was (374.9 \pm 69.3$)$ as clarified in figure(4). However of the few data that we find about the action of heroin or morphine derivatives on serum G6PDH, but ${ }^{(33)}$ used some drug of abuse in rats tissues in vitro, and they found similar results with ours. Also the addiction of nicotine suggested to reduce the activity of G6PDH enzyme in the liver ${ }^{(34)}$. The LDH measurements have been estimated by ${ }^{(35)}$ in heroin users and it was significantly higher than non-users.

Table (1): Serum Enzymatic, MDA and testosterone levels in control and heroin treated rats.

\begin{tabular}{|c|c|c|c|c|}
\hline Treatments & \multirow{2}{*}{ Control } & \multirow{2}{*}{ Heroin 1mg/kg } & \multirow{2}{*}{ Heroin 5mg/kg } & \multirow{2}{*}{ P-Values } \\
\hline Variables & & & & \\
\hline "Serum Xanthine Oxidase (U/ml) & $11.2 \pm 1.178^{\mathrm{a}}$ & $21.2 \pm 2.244^{b}$ & $30.4 \pm 2.158^{\mathrm{c}}$ & $(\mathbf{P}<0.05)$ \\
\hline Alkaline Phosphatase (U/L) & $9.49 \pm 1.06$ & $8.61 \pm 1.05$ & $6.11 \pm 0.77$ & N.S. \\
\hline $\begin{array}{c}\text { G6PDH ( } \mu \mathrm{mol} \text { of NADPH liberated } / \mathrm{min} / \mathrm{mg} \\
\text { protein) }\end{array}$ & $1.28 \pm 0.15^{\mathrm{a}}$ & $0.369 \pm 0.049^{b}$ & $0.246 \pm 0.29^{b}$ & $(\mathbf{P}<\mathbf{0 . 0 1})$ \\
\hline LDH (I.U./L) & $374.9 \pm 69.3^{\mathrm{a}}$ & $662.4 \pm 150.6^{b}$ & $1007.8 \pm 208.4^{\mathrm{c}}$ & $(\mathbf{P}<\mathbf{0 . 0 1})$ \\
\hline MDA $(\mu \mathrm{mol} / \mathrm{L})$ & $2.15 \pm 0.12^{a}$ & $2.62 \pm 0.23^{\mathrm{a}}$ & $3.63 \pm 0.15^{b}$ & $(\mathrm{P}<0.05)$ \\
\hline Testosterone (ng/ml) & $3.02 \pm 0.55^{b}$ & $0.57 \pm 0.078^{a}$ & $0.68 \pm 0.075^{\mathrm{a}}$ & $(\mathrm{P}<0.01)$ \\
\hline
\end{tabular}

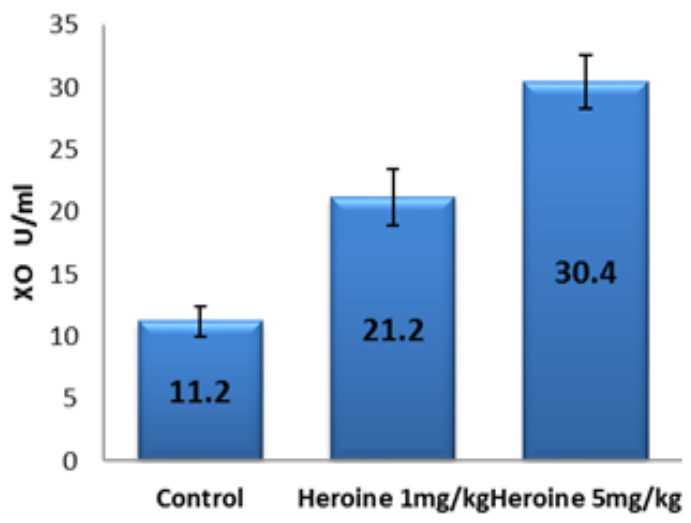

Figure (1): Xanthine Qxidase activity indifferent doses of heroin treatment

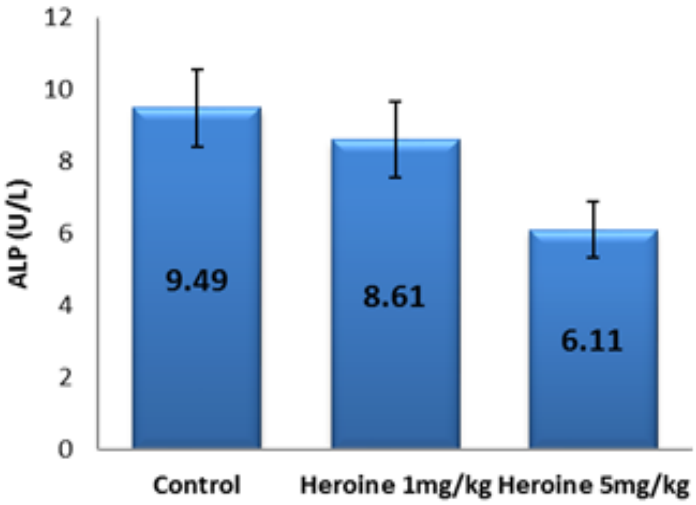

Figure (2): Alkaline phosphatase activity in different doses of heroin treatment 


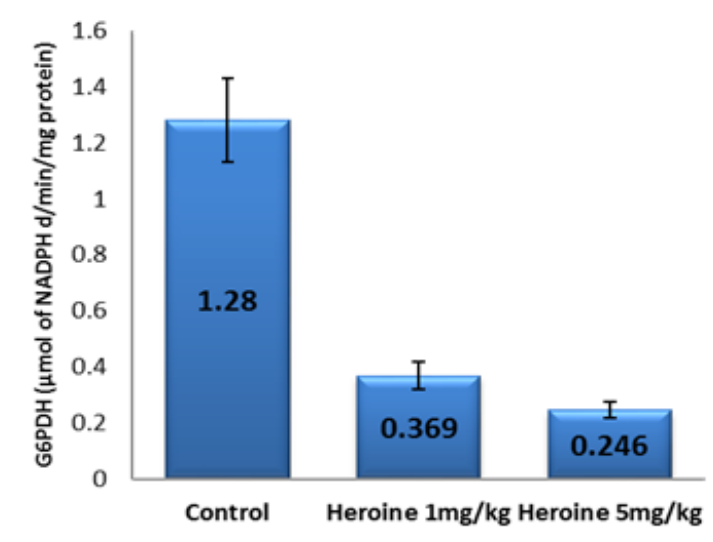

Figure (3): Glucose-6-phosphate dehydrogenase activity in different doses of heroin treatment

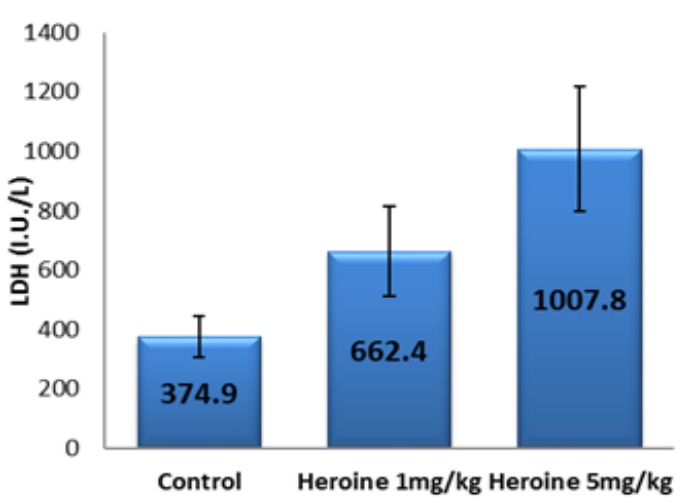

Figure (4): Lactate dehydrogenase activity in different doses of heroin treatment

\section{Effect of Heroin on the serum MDA activity}

The marker of lipid peroxidation was significantly elevated in sera of rats treated with the high dose of heroin $(5 \mathrm{mg})$ with mean $(3.63 \pm 0.15)$ as compared with control rats $(2.15 \pm 0.12)$, while $1 \mathrm{mg}$ heroin didn't show significant effect (Figure 5). Among the important toxic actions of drug abuse is the oxidative stress potential, and lipid peroxidation marker (MDA) is an indication of the balance of redox reaction in the body. Long-term heroin abuse stimulates a progressive systemic oxidative stress which increases the extracellular antioxidants consumption and develops conditions for chronic heroin toxicity ${ }^{(36)}$. Also ${ }^{(37)}$ concluded that the balance between oxidation and antioxidation in the heroin addicts was seriously destroyed, and the injuries induced by nitric oxide and other free radicals, oxidation, peroxidation and lipoperoxidation reactions to the body of heroin addicts gravely exacerbated. In the abstaining from heroin dependence, therefore, it should consider that sufficient quantum antioxidants such as vitamin $\mathrm{C}$, vitamin $\mathrm{E}$ and beta-Carotene are dosed to the heroin addicts so as to abate the injuries to their bodies.

\section{Testosterone level}

The result of current study reported that a dramatically reduction in testosterone level was occurred in heroin treated rats in both low and high doses. The level of testosterone in control group was $3.02 \pm 0.55 \mathrm{ng} / \mathrm{ml}$, while the level was dropped to $0.57 \pm 0.078$ and $0.68 \pm 0.075 \mathrm{ng} / \mathrm{ml}$ in rats treated with $1 \mathrm{mg}$ and $5 \mathrm{mg}$ heroin respectively as it is illustrated in figure (6). Heroin addiction has negative impacts on the female ${ }^{(38)}$ and male ${ }^{(39)}$ sexual hormones. Investigations in animals have demonstrated the acute and chronic effects of opioids on the endocrine system, ${ }^{(40)}$ including decreasing testosterone levels by central reductions of LH release (decreased hypothalamic release of luteinizing-hormone releasing hormone (LHRH), leading to reduced pituitary release of $\mathrm{LH}$ ), and peripheral effects on the testicle as well. ${ }^{(41)}$ Studies in heroin addicts, compared to healthy controls, have demonstrated decreased testosterone levels in males, with an associated decrease in LH and/or FSH consistent with central hypogonadism. ${ }^{(42)}$

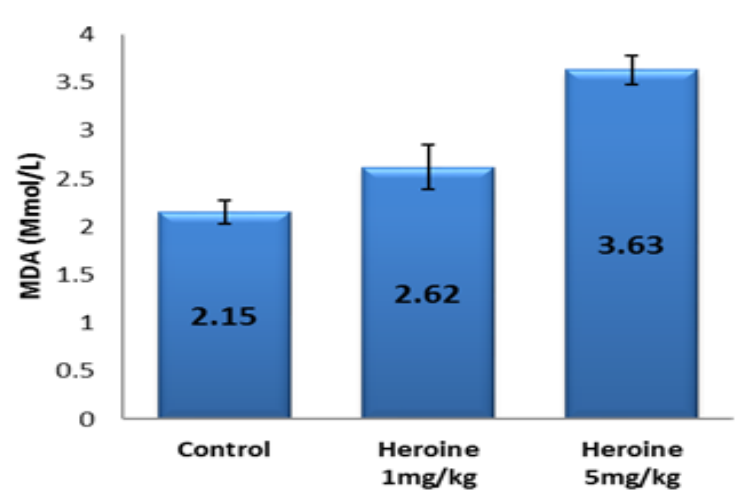

Figure (5): Malondialdehyde levels in different doses of heroin treatment

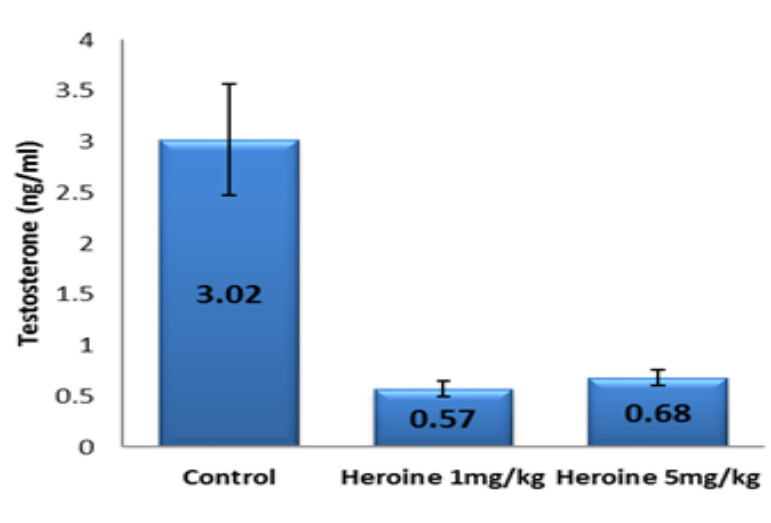

Figure (6): Testosterone hormone level in different doses of heroin treatment 


\section{Sperm Quality study}

The analyses of sperm head abnormalities were made after microscopic preparation of sperms and the counting of different head abnormalities. The results of sperm head abnormality counts showed that there was a high level of abnormality in the sperm head of rats treated with both doses of heroin, especially with high dose, as compared to control. The dominant type of abnormality was defective head and hook abnormalities (Figure 8), while normal sperms were observed in control group rats (Figure 7). The exposure of the rats to both $1 \mathrm{mg}$ and $5 \mathrm{mg}$ heroin caused $28.89 \%$ and $39.23 \%$ in sperm head abnormality respectively compared to $1.92 \%$ in control group. This finding suggests that addiction to opium has a lot of pathological effects on spermatogenesis which can cause infertility and low fertility in men, probably because of decrease in testosterone level related to possible suppressive effects of opium. ${ }^{(43)}$

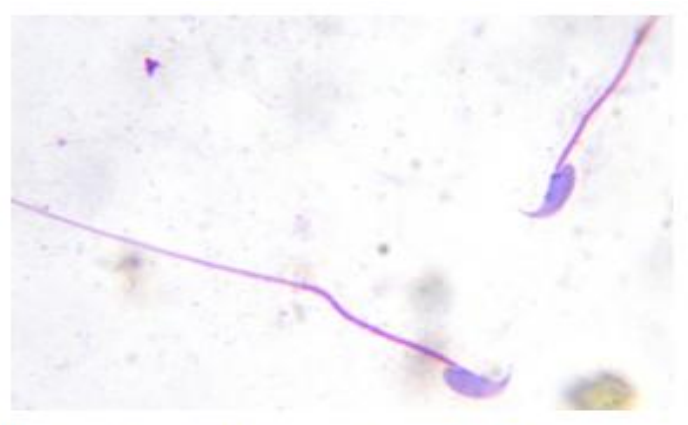

Figure (7): Normal sperms in control rats

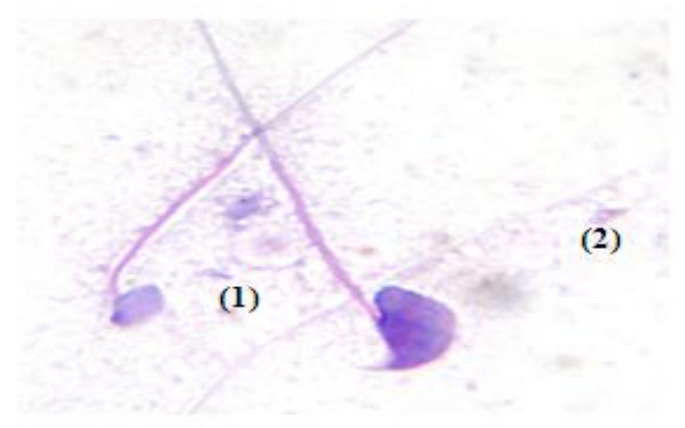

Figure (7): (1) Defective head and (2) blunt hook sperms in heroin treated rats

\section{Apoptotic cell count}

The counting of apoptotic cells in both doses heroin treated rats were significantly higher than in the control group $(p<0.05)$, while the frequency of apoptosis was non significantly increased in $5 \mathrm{mg}$ heroin treatment as compared to $1 \mathrm{mg}$ heroin treated rats (figure 9). The mean percent apoptotic hepatocytes in low dose of heroin was (3.5\%), while it was $(4.2 \%)$ in high dose of heroin as compared to control group (1.4\%). Several researches have been performed on the induction of cell death in CNS neurons ${ }^{(44-46)}$,but still little is known about the action of narcotic drugs on hepatocytes in vivo. ${ }^{(47)}$ showed that street heroin induces cell death by a mitochondrial-dependent apoptotic pathway, initiated by caspases 2 and 9, and involving cytochrome c release, loss of mitochondrial potential and down-regulation of Bcl-2. This process is not dependent on the activation of opioid or ionotropic glutamate receptors, nor is it dependent on oxidative stress.

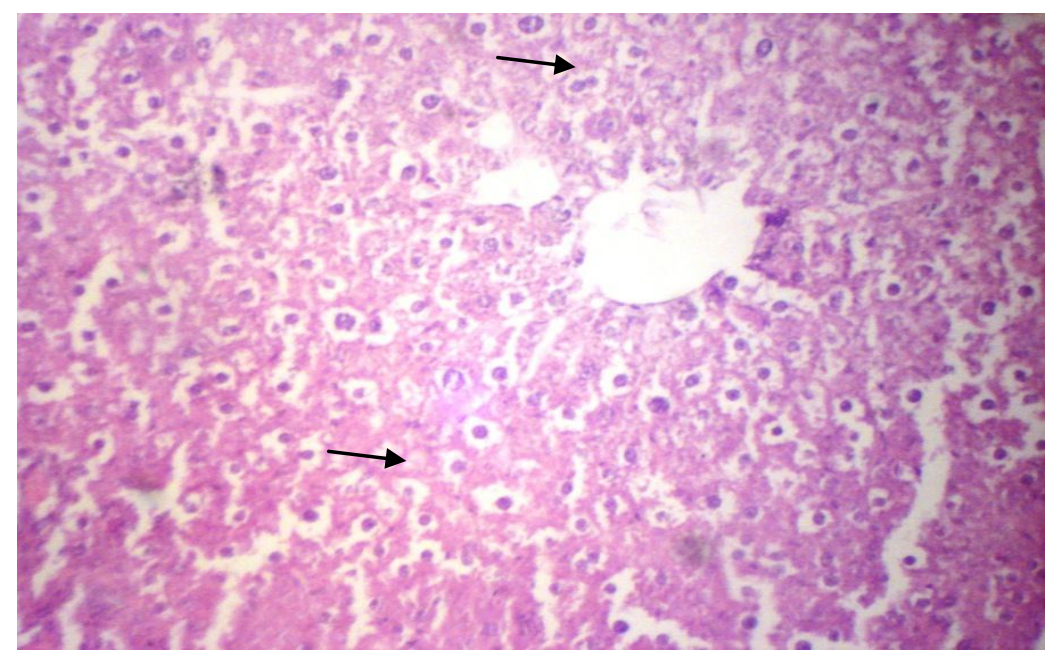

Figure (9): Hematoxylin \& Eosin-stained rat liver section taken from rats treated with $5 \mathrm{mg}$ heroin at a magnification of $400 \mathrm{X}$ (The arrows refers to apoptotic cells) 


\section{REFERENCES}

[1] Anderson RN. Deaths: leading causes for 1999. Natl Vital Stat Rep. 1999;49:1-88.

[2] Kuyper LM, Hogg RS, Montaner JSG, Schechter MT, Wood E. The Cost of Inaction on Hiv Transmission Among Injection Drug Users and the Potential for Effective Interventions. Journal of Urban Health-Bulletin of the New York Academy of Medicine. 2004;81:655-660. doi: 10.1093/jurban/jth148.

[3] Gowing L, Farrell M, Bornemann R, Sullivan L, Ali R. Substitution treatment of injecting opioid users for prevention of HIV infection. Cochrane Database Syst Rev. 2008. p. CD004145.

[4] CDC (2003) HIV diagnoses among injection-drug users in states with HIV surveillance--25 states, 1994-2000. MMWR Morb Mortal Wkly Rep 52, 634-636.

[5] Zhou J, Si P, Ruan Z, Ma S, Yan X, Sun L, Peng F, Yuan H, Cai D, Ding D, Xu S. Primary studies on heroin abuse and injury induced by oxidation and lipoperoxidation. Chin Med J (Engl). 2001 Mar;114(3):297-302.

[6] Zhou JF, Liu QJ, Ding DY. Correlation on heroin abuse and urinary 1 ipoperoxides contents. Chin J Neurol Psychiatr 1994;27:17-20.

[7] Zhou JF, Guo FZ, Ding DY. Explorative studies on urinary lipoperoxi des contents in heroin abusers. Chin Bull Drug Depend $1995 ; 4: 232-235$.

[8] Nair, M. P. N., Schwartz, S. A., Polasani, R., Hou, J., Swet, A., Chadha,K. C. (1997) Immunoregulatory effects of morphine on human lymphocytes.Clin. Diagnost. Lab. Immunol. 4, 127-132.

[9] Oyaizu, N., Adachi, Y., Hashimoto, F., McCloskey, T. W., Hosaka, N.,Kayagaki, N., Yagita, H., Pahawa, S. (1997) Monocytes express Fas ligand upon CD4 cross-linking and induce CD41 T cells apoptosis. J. Immunol. 158, 2456-2463.

[10] Singhal PC, Kapasi AA, Reddy K, Franki N, Gibbons N, Ding G. Morphine promotes apoptosis in Jurkat cells.J Leukoc Biol. 1999 Oct;66(4):650-8

[11] Azizi F, Vagenakis AG, Longcope C, Ingbar SH, Braverman LE 1973 Decreased serum testosterone concentration in male heroin and methadone addicts. Steroids 22:467-472

[12] Cicero TJ, Bell RD, Wiest WG, Allison JH, Polakoski K, Robins E 1975 Function of the male sex organs in heroin and methadone users. N Engl J Med 292:882-887.

[13] Daniell HW 2002 Narcotic-induced hypogonadism during therapy for heroin addiction. J Addict Dis 21:47-53.

[14] Davis CM, Rice KC, Riley AL. Opiate-agonist induced taste aversion learning in the Fischer 344 and Lewis inbred rat strains: evidence for differential mu opioid receptor activation. Pharmacol Biochem Behav. 2009 Oct;93(4):397-405. Epub 2009 Jun 7.

[15] Antonilli L, Suriano C, Paolone G, Badiani A, Nencini P. Repeated exposures to heroin and/or cadmium alter the rate of
formation of morphine glucuronides in the rat.J Pharmacol Exp Ther. 2003 Nov;307(2):651-60. Epub 2003 Sep 15.

[15] Antonilli L, Suriano C, Paolone G, Badiani A, Nencini P. Repeated exposures to heroin and/or cadmium alter the rate
formation of morphine glucuronides in the rat.J Pharmacol Exp Ther. 2003 Nov;307(2):651-60. Epub 2003 Sep 15.

[16] Vetulani J. Drug addiction. Part III. Pharmacotherapy of addiction.Pol J Pharmacol. 2001 Sep-Oct;53(5):415-34.

[17] Muslih, R.D.; Al-Nimer, O.M. and Al-Zamely, M.A. (2002). The level of Malondialdehyde after activation with (H2O2 and CuSO4) and inhibited by Desferoxamine and Molsidomine in the serum of patients with acute myocardial infection. Nat. J. Chem. 5:148-149.

[18] Wyrobek, A.J. Changes in Mammalian Sperm Morphology After X-ray and Chemical Exposures, Genetics, 1979, (Suppl) 91: 105-119.

[19] Bancroft, J .D.; Steven, A. and Dawson, I. Theory and Practice of Histological Techniques. Edinburgh, London, New York. Churchill-Livinstone, 1977.

[20] Acar, T., Ceyhan, K, Çolakoglu,T. Inhibition of Apoptosis Prevents Liver Failure and Improves Survival Rates after Extensive Hepatectomy in Rats. Acta chir belg, 2006 (106): 696-700.

[21] Li, K., He, H.T., Li, H.M., Liu, J.K., Fu, H.Y., Hong, M. Heroin affects purine nucleotides metabolism in rat brain. Neurochem Int. 2011;59(8):1104-8.

[22] Liu, C., Liu, J.K., Kan, M.J., Gao, L., Fu, H.Y., Zhou, H., Hong, M. Morphine enhances purine nucleotide catabolism in vivo and in vitro. Acta Pharmacol Sin. 2007; 28(8):1105-15.

[23] Ilic G, Karadzic R, Kostic Banovic L, Stioanovic J. Chronic intravenous heroin abuse: impact on the liver. Facta Universitatis Series: Medicine and Biology. 2005;12(3):1503.

[24] Fazelipour S, Kiaei SB, Tootian Z, Dashnavard H. Histomorphometric study of hepatocytes of mice after using heroin. International Journal of Pharmacology. 2008;4(6):496-9.

[25] Atici S, Cinel I, Cynel L, Doruk N, Escandari G, Oral U. Liver and kidney toxicity in chronic use of opioids: An experimental long term model. J Biosci. 2005;30(2):245-52.

[26] Ilic G, Karadzic R, Kostic Banovic L, Antonovic A. Amiloidosis, change in macrophage number and dysplasia in the liver of intravenous heroin users. Rom J Leg Med. 2011;19:27-32.

[27] Ilic G, Karadzic R, Kostic Banovic L, Stioanovic J. Influence of heroin on the hepatocyte glycogen content. Acta Fac Med Naiss. 2006;23(1):9-12.

[28] Trigueiro De Araujo MS, Gerard F, Chossegross P, Barlet P, Grimaud JA. Vascular hepatotoxicity related to heroin addiction. Virchows Arch A Pathol Anat. 1990;417:497-503.

[29] Trigueiro De Araujo MS, Gerard F, Chossegross P, Guerret S, Barbt P, Adeline P, Grimand JA. Cellular and matrix changes in drug abusers liver sinusoids: a semi-quantitative and morphometricultrastructural study. Virchows Arch A Pathol Anat Histopathol. 1993;422(2):145-52.

[30] Korolenko TA, Goncharova IA, Anterejkina LI, Levina OA, Korolenko CP. Influence of opiate addiction on liver cell damage of patients with viral hepatitis C. Alaska Med. 2007;49(2 Suppl):75-8. [In Russian]

[31] Wasmuth JC. Epidemiology, trasmission and natural history. In: Mauss S, Berg T, Rockstroh J, Sarrazin C, Wedemeyer H, editors. Short Guide to Hepatitis C. Flying Publisher; 2011. p. 13-18.

[32] Tennant F, Moll D.J Seroprevalence of hepatitis A, B, C, and D markers and liver function abnormalities in intravenous heroin addicts. Addict Dis.1995;14(3):35-49.

[33] Ebru Akkemik, Harun Budak, Mehmet Ciftci. Effects of some drugs on human erythrocyte 6-phosphogluconate dehydrogenase: an in vitro study. J Enzyme Inhib Med Chem. 2010 Mar 17;: 20235752.

[34] Mehmet Ciftci, Hayrullah Yilmaz, T Abdulkadir Coban, Mustafa Gul, Kenan Gumustekin, Senol Dane. Effects of nicotine and vitamin $\mathrm{E}$ on 6-phosphogluconate dehydrogenase activity in some rat tissues in vivo and in vitro. J Enzyme Inhib Med Chem. 2008 Apr ;23 (2):261-5.

[35] Kosmadakis G, Michail O, Filiopoulos V, Papadopoulou P, Michail S. Acute kidney injury due to rhabdomyolysis in narcotic drug users. Int J Artif Organs. 2011 Jul;34(7):584-8. 
[36] Pereska Z, Dejanova B, Bozinovska C, Petkovska L. Prooxidative/antioxidative homeostasis in heroin addiction and detoxification. Bratisl Lek Listy. 2007;108(9):393-8.

[37] Gutowicz M, Sadurska B, Chołojczyk M, Pokorska-Lis M, Siwińska-Ziółkowska A, Barańczyk-Kuźma A. Antioxidant status in different regions of heroin addicts' brain. Environ Toxicol Pharmacol. 2006 Jan;21(1):80-5.

[38] Malik SA, Khan C, Jabbar A, Iqbal A. Heroin addiction and sex hormones in males. J Pak Med Assoc. 1992 Sep;42(9):210-2.

[39] Wisniewski AB, Brown TT, John M, Frankowicz JK, Cofranceso J Jr, Golub ET, Ricketts EP, Dobs AS. Hypothalamic-pituitarygonadal function in men and women using heroin and cocaine, stratified by HIV status. Gend Med. 2007 Mar;4(1):35-44.

[40] Yilmaz B, Knoar V, Kutlu S, et al. Influence of chronic morphine exposure on serum LH, FSH, testosterone levels, and body and testicular weights in the developing male rat. Arch Androl 1999 Nov-Dec 31;43(3):189-96.

[41] Adams ML, Sewing B, Forman JB, Meyer ER, Cicero TJ. Opioidinduced suppression of rat testicular function. J Pharmacol Exp Ther 1993;266(1):323-8.

[42] Daniell HW. Narcotic-induced hypogonadism during therapy for heroin addiction. J Addict Dis 2002;21(4):47-53.

[43] Moradi, A., Sharamian, I. Sharafi. E. Opium effect on spermatogenesis of addicted men. International Conference on Life Science and Technology IPCBEE vol.3 (2011).

[44] Lai B, Pu H, Cao Q, Jing H, Liu X. Activation of caspase-3 and c-Jun NH2-terminal kinase signaling pathways involving heroininduced neuronal apoptosis. Neurosci Lett. 2011 Sep 20;502(3):209-13. doi: 10.1016/j.neulet.2011.07.046. Epub 2011 Aug 10.

[45] Lu PY, Li ZH, Guo Y, Jing HL, Lin WY, Liu XS. The suppression of c-fos in neuron apoptosis induced by heroin. Fa Yi Xue Za Zhi. 2010 Oct;26(5):321-4.

[46] Perez-Alvarez S, Iglesias-Guimarais V, Solesio ME, Melero-Fernandez de Mera RM, Yuste VJ, Galindo MF, Jordán J. Methadone induces CAD degradation and AIF-mediated necrotic-like cell death in neuroblastoma cells. Pharmacol Res. 2011 Apr;63(4):352-60.

[47] Cunha-Oliveira, T. Cristina Rego, A. , Jorge Garrido, A., Borges,F. Street heroin induces mitochondrial dysfunction and apoptosis in rat cortical neurons. Journal of Neurochemistry, 2007, 101, 543-554. 